\title{
BUILDING AND SOLVING THE HEAT TRANSFER MODELS TO DETERMINE SUITABLE FRYING CONDITIONS FOR INSTANT NOODLES
}

\author{
Linh T.K. Vu¹, Duy Quang Nguyen', Dao Thi Anh Phan¹, Dzung Tan Nguyen ${ }^{1 凶}$ \\ Department of Food Technology, Faculty of Chemical and Food Technology, HCMC University of Technology \\ and Education, No 01-Vo Van Ngan Street, Thu Duc City, Ho Chi Minh City, Viet Nam. \\ \tandzung072@hcmute.edu.vn \\ https://doi.org/10.34302/crpjfst/2021.13.4.9 \\ Article history: \\ Received: \\ 12 March 2021 \\ Accepted: \\ 2 October 2021 \\ Keywords: \\ Frying process; \\ Frying technolog; \\ Instant noodles; \\ Heat transfer model; \\ Mathematical model.

\begin{abstract}
The purpose of this study is to build a mathematical model of unstable heat transfer describing the frying process of instant noodle products, and this unstable heat transfer mathematical model was solved to determine the relationships between frying temperature and radius of fried noodle strands, between frying temperature and frying time. The obtained results were then used to simulate the frying kinetics, establish the frying conditions for instant noodles, and could be used to design instant noodle frying equipment. The results of solving the mathematical model established the frying conditions for instant noodles as follows: instant noodle strands had a radius of $1 \mathrm{~mm}$, frying temperature was $150^{\circ} \mathrm{C}$ in oil, and frying time was $90 \mathrm{~s}$. At these conditions, experimental results confirmed that the temperature of frying noodles reached $150{ }^{\circ} \mathrm{C}$, and the moisture content of the fried products was satisfactorily $1.8 \%$; the fried noodles were crispy with a beautiful yellow color, the reconstitution ability in boiling water was significantly improved.
\end{abstract} \\ ABSTRACT
}

\section{Introduction}

In the hurry of modern life, instant noodles have become indispensable food products not only in Vietnamese but also in other countries (Saguy and Dana, 2003). Currently, a number of factories produce instant noodles according to the manufacturing process shown in Fig.1.Instant noodle making process.

Ingredients: The most popular types of noodles in the world are Chinese-, Japaneseand European-style instant noodles. Basic ingredients of instant noodles include wheat flour, starch, water, salt or kansui (an alkaline salt mixture of sodium carbonate, potassium carbonate and sodium phosphate) and other ingredients that help improve the texture and flavor of the noodles. Kansui is normally used in Chinese instant noodles but not in Japanese noodles. European-style noodles are usually made from semolina, a type of flour that is coarsely ground from durum wheat. In addition, it is possible to mix other flours with wheat flour to create different types of instant noodles such as buckwheat flour $(10-40 \%)$ in the production of soba (Benu, Adhikari, Xiaotian, Zhang, Min, Zhang., 2020).

Preparation of the dough: The first step in noodle production is dissolving salt or kansui, starch, flavoring and other ingredients (except wheat flour) into water. Wheat flour is then added and the mixture is kneaded until a dough of desired toughness is obtained. After that, the dough is rested for $20-40$ mins to make it smoother and less streaky after sheeting (Pankaj and Keene., 2017).

Sheeting - Slitting - Waving: After incubation, the dough is passed to a sheeter to gauge the dough mass into a sheet. The dough sheet then passes through a series of 4-6 pairs of rollers with decreasing gaps to facilitate the development of the gluten network and to reduce the thickness of the dough sheet to that 
required for slitting. The wavy pattern of noodle strands is created by setting the conveyor speed to be slower than the cutting roll speed in the previous step. In addition, the interference by the metal blocks of the cutting machine also contributes to the noodle waves (Akinsola et al., 2018; Shashi K.Pankaj, Kevin MKeene., 2017).

Steaming: Sometimes, noodle strands are dipped into a mixture of liquid spices before being quantitatively cut and molded into blocks or shapes which are suitable for consumption purposes. The noodles are then steamed at $100^{\circ} \mathrm{C}$ for $1-5$ minutes to gelatinize the starch and improve the texture of the noodle strands (Akinsola et al., 2018).

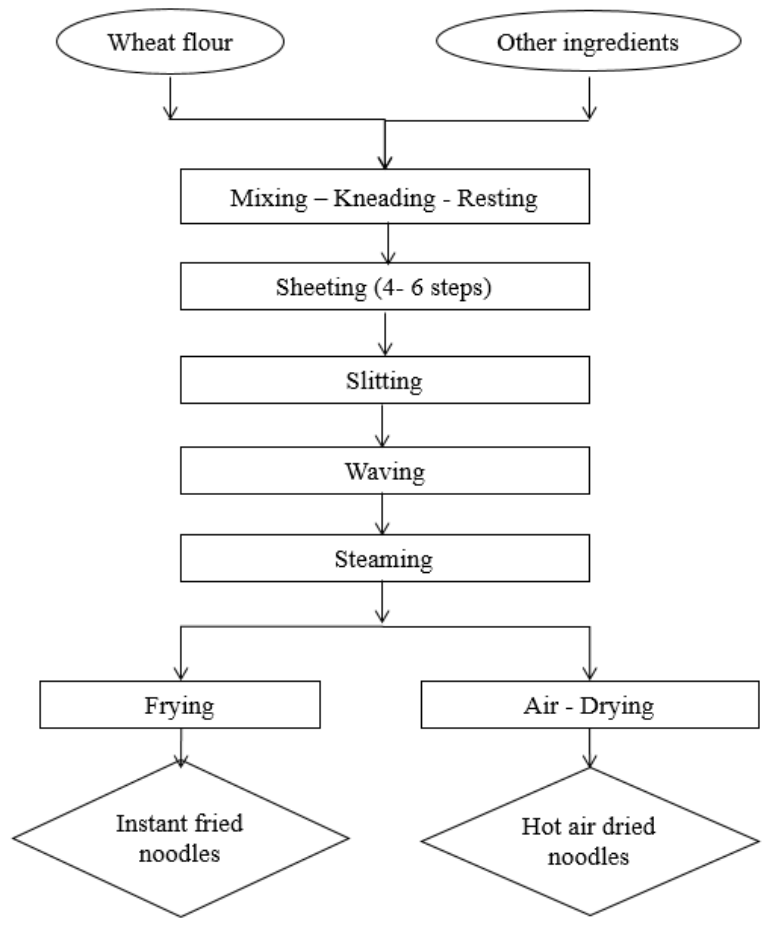

Figure 1. Instant noodle making process ( Akinsola et al., 2018)

Drying of noodle (Frying or Drying)

Frying/drying: After steaming stage, noodles are dried by frying in oil (Fried instant noodles) or drying with hot air (Non-fried instant noodles). Frying noodles in oil at 140$160{ }^{\circ} \mathrm{C}$ for $1-2$ minutes reduces the moisture content of noodles from 30-50 \% (after steaming) to about 2-5\%. Palm oil is commonly used in Asia, while the mixture of canola oil, cottonseed oil and palm oil is often used in North America A. (Akinsola et al., 2018).

With the drying method, noodles are kept in hot air at $70-90{ }^{\circ} \mathrm{C}$ for $30-40$ minutes to reach $8-12 \%$ of moisture. Both the frying or drying process improves the starch gelatinization and the spongy texture of the noodles. Frying method is more preferred than drying, and up to $80 \%$ of the noodle products on the market are fried noodles. The disadvantage of air-drying process is the uneven exposure noodle strands to the hot air and this adversely affects the texture of the finished noodles (Bouchon, P., et al., 2003; Akinsola, et al., 2018). Non-fried noodles also require a longer cooking time. However, one drawback of frying is that the fried noodles contain about 15 - $20 \%$ of lipid as compared to that of air-dried noodles (about 3\%). Thus, fried noodles are more susceptible to lipid oxidation and deterioration. Nevertheless, antioxidants could be used to extend the shelflife of fried noodles (Bouchon, P., et al., 2003).

Cooling and packaging: the dried noodles are quickly cooled, and then examined for the moisture content, color, shape and other quality properties. The finished blocks of noodles will be packed with different pouches of seasonings. There are two types of product packaging: the bag-type and the cup-type (Akinsola, et al., 2018).

Today, instant noodles are availabe in a wide range of flavors such as pork, beef, chicken, shrimp flavors as well as other vegetarian variations to serve diverse needs of consumers. Due to their low moisture content, instant noodles have high stability and a shelf life of 4 - 6 months in the tropics and about 612 months in the Northern hemisphere. They can be used immediately after boiling in water for 1- 2 minutes or soaking in hot water for 3- 4 minutes (Costa, R. M., et al., 1999).

Through the literature review it can be seen that the frying process in which noodles are fried in cooking oil at $140-160^{\circ} \mathrm{C}$ for $1-2$ minutes to reduce the moisture content from $35-55 \%$ (at the steaming stage) to about 2-5\% has not been substantially studied in terms of 
building methamatical models to accurately determine suitable frying conditions (Costa et al., 1999; Akinsola et al., 2018). This is an important stage to decide the quality of the product because if the frying temperature is low, the fried time is short, the fried noodles would not reach the required moisture content; if the frying temperature is high, the noodles would be burnt, leading to an increase in production cost (Bouchon, P., et al., 2003; Gertz, C., 2014). Hence, it is necessary to to establish and solve mathematical models to determine the frying conditions (e.g. frying temperature and fyring time) for instant noodles, so that fried the noodles could obtained good quality and production cost is reduced.

\section{Matherials and methods}

\section{Building and solving descriptive} mathematical models for the frying process

\subsection{Assumptions}

- Problem analysis

The frying process increases the noodle temperature from $\mathrm{t}_{0}=25{ }^{\circ} \mathrm{C}$ (room temperature) to $t_{e}=150^{\circ} \mathrm{C}$ (the boiling point of cooking oil, or fried temperature). Hence, the noodles strands are cooked and microorganisms are kills through this heating process. The research questions here are: (1) How does the average temperature of noodle strands vary over frying time?, and (2) How long should the frying time be? Because if the frying time is not enough, the noodles are undercooked; on the other hand, long frying time would adversely affect quality of the final product. These are hence very important issues in instant noodle production technology (Dzung, N.T., 2012).

- Model the system as an object model, determine the actual geometrical dimensions of the object model
Assume that the instant noodle strands have cylindrical shape with the following dimensions:

- Radius: $\mathrm{R}=1 \mathrm{~mm}=0.001 \mathrm{~m}$.

- Length: infinitely long ( $\mathrm{L}>>\mathrm{R})$.

- Assume that shape and size of noodle strands are unchanged during the frying process.

- Noodles have concentric isothermal surfaces, meaning that a set of points that are equidistant from the center, with the same inner radius will have the same temperature.

- Set up assumptions of physicochemical systems associated with actual conditions before building the mathematical model, determine the physical and chemical properties affecting the technological process

- The temperature field is distributed in the noodle in the radial direction $\mathrm{T}(\mathrm{r}, \tau)$, whose isothermal surfaces are concentric cylindrical surfaces.

- The initial temperature of the noodle strand is $\mathrm{T}_{0}=25{ }^{\circ} \mathrm{C}=298 \mathrm{~K}$, and it is suddenly placed into an environment with constant temperature $\mathrm{T}_{\mathrm{e}}=150^{\circ} \mathrm{C}=443 \mathrm{~K}$.

- Frying conditions: use shortening oil whose temperature remains constant during heat transfer and is equal to the boiling point of shortening oil, $150{ }^{\circ} \mathrm{C}\left(\mathrm{T}_{\mathrm{e}}=443 \mathrm{~K}=\right.$ const $)$.

- The internal heat source of the noodle strand at the beginning is $\mathrm{q}_{\mathrm{v}}=700-0.1 \mathrm{~T}$, W.m ${ }^{-3}$ (Heldman and Lund, 1992).

- The process may be assumed to be an unstable heating in the symmetrical cylinder, under boundary condition type 1 , with the same heat emission coefficient of the environment surrounding the object, and the boiling point of shortening is considered constant during the heat transfer. 
- Heat emission coefficient of shortening is $\alpha$ $=100 \mathrm{~W} \cdot \mathrm{m}^{-2} \cdot \mathrm{K}^{-1}$, (Heldman and Lund, 1992).

- Physical conditions: thickness $\delta=2 \mathrm{R}=2$ $\mathrm{mm}=2 \times 10^{-3} \mathrm{~m}$; density $\rho=1100 \mathrm{~kg} \cdot \mathrm{m}^{-3}$; thermal conductivity $\lambda=0.45 \mathrm{~W} \cdot \mathrm{m}^{-1} \cdot \mathrm{K}^{-1}$; specific heat $c_{\mathrm{p}}=2930.79 \mathrm{~J} \cdot \mathrm{kg}^{-1} \cdot \mathrm{K}^{-1}$, (Heldman and Lund, 1992).

- To facilitate the calculation process, it is assumed that the total frying time is: $\tau_{\mathrm{o}}=$ 90s.

\subsection{Building mathematical model}

Based on the energy balance equation, the heat transfer model in the case of having an internal heat source is established as follows (Holman, 1992):

$$
\left\{\begin{array}{l}
\frac{\partial \mathrm{T}(\mathrm{r}, \tau)}{\partial \tau}=\mathrm{a}\left(\frac{\partial^{2} \mathrm{~T}(\mathrm{r}, \tau)}{\partial \mathrm{r}^{2}}+\frac{1}{\mathrm{r}} \frac{\partial \mathrm{T}(\mathrm{r}, \tau)}{\partial \mathrm{r}}\right)+\frac{\mathrm{q}_{\mathrm{V}}}{\rho \mathrm{C}_{\mathrm{p}}} \\
-\mathrm{R} \leq \mathrm{r} \leq \mathrm{R}
\end{array}\right.
$$

Initial and boundary conditions to solve equation system (1):

- Initial condition:

$$
\mathrm{T}_{0}(\mathrm{r}, 0)=25^{\circ} \mathrm{C}=298 \mathrm{~K}=\text { const }
$$

- Frying temperature:

$$
\mathrm{T}(\mathrm{r}, \tau)=\mathrm{T}_{\mathrm{e}}=\mathrm{const}
$$

- Boundary conditions:

$$
\begin{aligned}
& \left.\frac{\partial \mathrm{T}(\mathrm{r}, \tau)}{\partial \mathrm{r}}\right|_{\mathrm{r}=\mathrm{R}}=-\frac{\alpha}{\lambda}\left[\mathrm{T}_{\mathrm{e}}-\mathrm{T}(\mathrm{r}, \tau)\right] \\
& \left.\frac{\partial \mathrm{T}(\mathrm{r}, \tau)}{\partial \mathrm{r}}\right|_{\mathrm{r}=0}=0
\end{aligned}
$$

\subsection{Solving mathematical model}

Using Fourier variable separation method to solve the system of equations (1) - (5), the dimensionless temperature $\theta$ was found as follows (Holman, 1992):

$$
\begin{aligned}
\bar{\theta} & =\frac{t(\tau)-t_{o}}{t_{e}-t_{o}}=1+\frac{P_{o}}{4}\left(1+\frac{2}{B i}-\frac{r^{2}}{R^{2}}\right) \\
& -\sum_{n=0}^{\infty}\left(1+\frac{P_{o}}{\mu_{n}^{2}}\right) A_{n} \mathrm{~J}_{o}\left(\mu_{n} \frac{x}{R}\right) \exp \left(-\mu_{n}^{2} F_{o}\right)
\end{aligned}
$$

where:

$$
\begin{aligned}
& P_{o}=\frac{q_{v} R^{2}}{\lambda\left(T_{e}-T_{\mathrm{o}}\right)}=\frac{(700-0.1 T) R^{2}}{\lambda\left(T_{e}-T_{\mathrm{o}}\right)} \\
& F_{O}=\frac{a \tau}{R^{2}}
\end{aligned}
$$

The dimensionless average temperature $\bar{\theta}$ of the cylindrical noodle strands is:

$$
\begin{aligned}
\bar{\theta}= & \frac{\bar{t}(\tau)-t_{o}}{t_{e}-t_{o}}=1+\frac{P_{o}}{8}\left(1+\frac{4}{B i}\right) \\
& -\sum_{n=0}^{\infty}\left(1+\frac{P_{o}}{\mu_{n}^{2}}\right) B_{n} \exp \left(-\mu_{n}^{2} F_{O}\right)
\end{aligned}
$$

with:

$$
\begin{aligned}
& A_{n}=\frac{2 . B i}{J_{o}\left(\mu_{n}\right)\left[\mu_{n}^{2}+B i^{2}\right]} \\
& B_{n}=\frac{4 . B i^{2}}{\mu_{n}^{2}\left[\mu_{n}^{2}+B i^{2}\right]}
\end{aligned}
$$

$\mu_{n}$ - roots of specific equation:

$$
\frac{J_{0}\left(\mu_{n}\right)}{J_{1}\left(\mu_{n}\right)}=\frac{\mu_{n}}{B i}
$$

Bi: Biot number

$$
\mathrm{Bi}=\frac{\alpha \mathrm{R}}{\lambda}
$$

Fo: Fourier number

$$
\mathrm{Fo}=\frac{\mathrm{a} \tau}{\mathrm{R}^{2}}
$$

$\mathrm{J}_{0}\left(\mu_{\mathrm{n}}\right), \mathrm{J}_{1}\left(\mu_{\mathrm{n}}\right)$ : Bessel functions type 1 of the zero and first order.

$$
\mathrm{J}_{0}(\mathrm{x})=1-\left(\frac{1}{2} \mathrm{x}\right)^{2}+\frac{\left(\frac{1}{2} \mathrm{x}\right)^{4}}{1^{2} \cdot 2^{2}}-\frac{\left(\frac{1}{2} \mathrm{x}\right)^{6}}{1^{2} \cdot 2^{2} \cdot 3^{2}}+\frac{\left(\frac{1}{2} \mathrm{x}\right)^{8}}{1^{2} \cdot 2^{2} \cdot 3^{2} \cdot 4^{2}}-\ldots
$$




$$
\mathrm{J}_{1}(\mathrm{x})=-\mathrm{J}_{0}^{\prime}(\mathrm{x})=\frac{1}{2} \mathrm{x}-\frac{\left(\frac{1}{2} \mathrm{x}\right)^{3}}{1^{2} \cdot 2}+\frac{\left(\frac{1}{2} \mathrm{x}\right)^{5}}{1^{2} \cdot 2^{2} \cdot 3}-\frac{\left(\frac{1}{2} \mathrm{x}\right)^{7}}{1^{2} \cdot 2^{2} \cdot 3^{2} \cdot 4}+\ldots
$$

\subsection{Materials}

This research only studied the frying process of raw noodle strands after steaming step. Raw noodle strands were provided by Asiafood Company, which had been prepared by the following steps: mechanical dough mixing, sheeting, cutting into strands, waving, shaping and steaming. Raw noodle strands were uniform in size and shape, with the radius $\mathrm{R}=1 \mathrm{~mm}=0.1 \mathrm{~cm}$ (Figure 2). They were then fried to dehydrate and to increase the crispness.

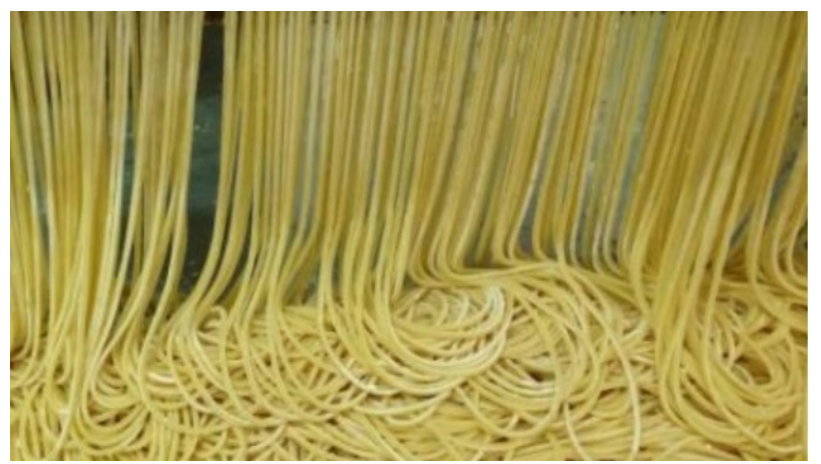

Figure 2. Fresh, un-waved and un-fried noodle strands

\subsection{Apparatus}

- The deep fryer DVF-04 made by Ho Chi Minh City University of Technology and Education, Vietnam in 2019 was used to perform the study. This is a conveyor frying system (Figure 3).

- The DVF-04 can automatically measure the technological parameters as: temperatures of frying oil and products, frying time, conveyor speed. The equipment was controlled by programs on the computer.

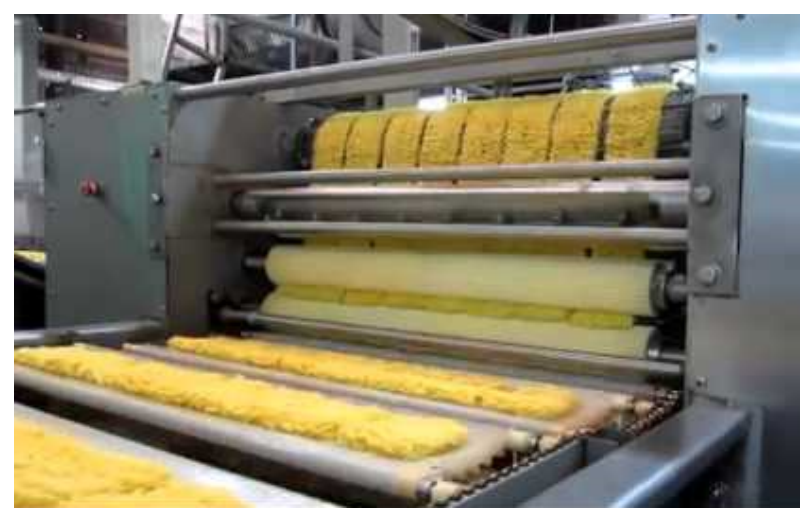

Figure 3. The deep fryer DVF--04

\subsection{Methods}

- In this study, the problem analysis and systematic approach were used to build mathematical models (Figura and Teixeira, 2007).

- Modeling and optimization methods were used to build and solve descriptive mathematical models for instant noodle frying process (Figura and Teixeira, 2007).

- The moisture content was determined by drying to a constant weight, the result was calculated using the following equation (Figura and Teixeira, 2007):

$$
W_{e}=100-\frac{G_{o}}{G_{e}}\left(100-W_{o}\right)
$$

where: $G_{0}(g)$ - weight of the sample before frying; $\mathrm{G}_{\mathrm{e}}(\mathrm{g})$ - weight of the sample after frying; $\mathrm{W}_{\mathrm{o}}(\%)$ - initial moisture content of the sample before frying; $\mathrm{W}_{\mathrm{e}}(\%)$ - moisture content of the sample after frying.

- Mathematical tools and softwares such as Microsoft Excel 2020, Matlab 7.0 and Visual Basic 8.0 were used to establish and solve the mathematical models (Dzung et al., 2012a; 2012b). 


\section{Results and discussions}

\subsection{Solving specific equation (12)}

With the division algorithm programmed by Visual Basic 8.0 software, the solution of the characteristic equation were found as (12):

$\mu_{1}=2.4048 ; \mu_{2}=5.5201 ; \mu_{3}=8.6538 ; \mu_{4}=$ $11.7915 ; \mu_{5}=19.256$;

with:

$$
a=\frac{\lambda}{c_{p} \rho}=\frac{0.45}{2930.79 \times 1100}=1.395 \times 10^{-7} \mathrm{~m}^{2} / \mathrm{s}
$$

Substitute $\mathrm{a}=1.395 \times 10^{-7} \mathrm{~m}^{2} / \mathrm{s}$ into equation (14) to determine the Fourier's standard number.

Substitute (7), (13), (14) and roots of specific equation (12) in Table 1 into equation (9). The results showed that: equation (9) quickly converged to 0 when $n>4$.

$$
\sum_{n=0}^{\infty}\left(1+\frac{P_{o}}{\mu_{n}^{2}}\right) B_{n} \exp \left(-\mu_{n}^{2} F_{o}\right) \rightarrow 0
$$

Therefore, at $\mathrm{n}=4$, roots of specific equation (12) are presented in Table 1 as follows:

Table 1. Roots of specific equation (12)

\begin{tabular}{|c|c|c|c|}
\hline$\mu_{1}$ & $\mu_{2}$ & $\mu_{3}$ & $\mu_{4}$ \\
\hline 2.4048 & 5.5201 & 8.6538 & 11.7915 \\
\hline
\end{tabular}

\subsection{Determination of frying temperature of} instant noodle

- Substitute equations (11), (13) and (14), roots of specific equation (12) in Table 1 into equation (9). Using the Visual Basic language programmed in Macro in Microsoft Excel 2020 (Dzung et al., 2012a), $\bar{\theta}$ was calculated and it was found out that the average temperature of noodles strands $\bar{t}(\mathrm{r}, \tau)$ varied according to the radius from the fixed center of the noodle strand and the frying time.

- Given the frying time at 10 different values as $\tau=10 \mathrm{~s}, 20 \mathrm{~s}, 30 \mathrm{~s}, 40 \mathrm{~s}, 50 \mathrm{~s}, 60 \mathrm{~s}, 70 \mathrm{~s}$, $80 \mathrm{~s}, 90 \mathrm{~s}, 100 \mathrm{~s}$ to calculate $\bar{t}(\mathrm{r}, \tau)=\bar{t}(\mathrm{r})$ at each frying time; the obtained results are shown in Table 2a, Table $2 b$ and Table 2c:

Table 2a. Variation of temperature according to $r$ at different frying times

\begin{tabular}{|c|c|c|c|c|}
\hline \multirow{2}{*}{$\mathrm{r}$} & \multicolumn{4}{|c|}{ Temperature after $\tau$ (s) of frying } \\
\cline { 2 - 5 } & $10 \mathrm{~s}$ & $20 \mathrm{~s}$ & $30 \mathrm{~s}$ & $40 \mathrm{~s}$ \\
\hline 0.00000 & 61.04 & 109.49 & 131.92 & 141.93 \\
\hline 0.00005 & 61.33 & 109.64 & 131.98 & 141.96 \\
\hline 0.00010 & 62.21 & 110.08 & 132.18 & 142.05 \\
\hline 0.00015 & 63.66 & 110.80 & 132.50 & 142.19 \\
\hline 0.00020 & 65.69 & 111.80 & 132.95 & 142.39 \\
\hline 0.00025 & 68.27 & 113.06 & 133.52 & 142.65 \\
\hline 0.00030 & 71.39 & 114.58 & 134.20 & 142.95 \\
\hline 0.00035 & 75.03 & 116.34 & 134.98 & 143.30 \\
\hline 0.00040 & 79.18 & 118.32 & 135.87 & 143.69 \\
\hline 0.00045 & 83.78 & 120.49 & 136.84 & 144.13 \\
\hline 0.00050 & 88.81 & 122.84 & 137.89 & 144.60 \\
\hline 0.00055 & 94.22 & 125.34 & 139.00 & 145.09 \\
\hline 0.00060 & 99.96 & 127.96 & 140.17 & 145.62 \\
\hline 0.00065 & 105.97 & 130.68 & 141.39 & 146.16 \\
\hline 0.00070 & 112.20 & 133.47 & 142.63 & 146.71 \\
\hline 0.00075 & 118.56 & 136.29 & 143.89 & 147.27 \\
\hline 0.00080 & 125.00 & 139.13 & 145.15 & 147.84 \\
\hline 0.00085 & 131.44 & 141.95 & 146.41 & 148.40 \\
\hline 0.00090 & 137.80 & 144.71 & 147.64 & 148.95 \\
\hline 0.00095 & 144.01 & 147.41 & 148.84 & 149.48 \\
\hline 0.00100 & 150.00 & 150.00 & 150.00 & 150.00 \\
\hline
\end{tabular}

Table 2b. Variation of temperature according to $r$ at different frying times

\begin{tabular}{|c|c|c|c|}
\hline \multirow{2}{*}{$\mathrm{r}$} & \multicolumn{3}{|c|}{$\begin{array}{c}\text { Temperature after } \tau \text { (s) of frying } \\
\text { noodles }\end{array}$} \\
\cline { 2 - 4 } & $50 \mathrm{~s}$ & $60 \mathrm{~s}$ & $70 \mathrm{~s}$ \\
\hline 0.00000 & 146.40 & 148.40 & 149.28 \\
\hline 0.00005 & 146.42 & 148.40 & 149.29 \\
\hline 0.00010 & 146.45 & 148.42 & 149.29 \\
\hline 0.00015 & 146.52 & 148.45 & 149.31 \\
\hline 0.00020 & 146.61 & 148.49 & 149.33 \\
\hline 0.00025 & 146.72 & 148.54 & 149.35 \\
\hline 0.00030 & 146.86 & 148.60 & 149.37 \\
\hline
\end{tabular}


Vu et al./ Carpathian Journal of Food Science and Technology, 2021, 13(4), 105-115

\begin{tabular}{|l|l|l|l|}
\hline 0.00035 & 147.01 & 148.67 & 149.41 \\
\hline 0.00040 & 147.19 & 148.75 & 149.44 \\
\hline 0.00045 & 147.38 & 148.83 & 149.48 \\
\hline 0.00050 & 147.59 & 148.92 & 149.52 \\
\hline 0.00055 & 147.81 & 149.02 & 149.56 \\
\hline 0.00060 & 148.04 & 149.13 & 149.61 \\
\hline 0.00065 & 148.29 & 149.24 & 149.66 \\
\hline 0.00070 & 148.53 & 149.35 & 149.71 \\
\hline 0.00075 & 148.78 & 149.46 & 149.76 \\
\hline 0.00080 & 149.04 & 149.57 & 149.81 \\
\hline 0.00085 & 149.29 & 149.68 & 149.86 \\
\hline 0.00090 & 149.53 & 149.79 & 149.91 \\
\hline 0.00095 & 149.77 & 149.90 & 149.95 \\
\hline 0.00100 & 150.00 & 150.00 & 150.00 \\
\hline
\end{tabular}

\begin{tabular}{|l|l|l|l|}
\hline 0.00070 & 149.87 & 149.94 & 149.97 \\
\hline 0.00075 & 149.89 & 149.95 & 149.98 \\
\hline 0.00080 & 149.91 & 149.96 & 149.98 \\
\hline 0.00085 & 149.94 & 149.97 & 149.99 \\
\hline 0.00090 & 149.96 & 149.98 & 149.99 \\
\hline 0.00095 & 149.98 & 149.99 & 150.00 \\
\hline 0.00100 & 150.00 & 150.00 & 150.00 \\
\hline
\end{tabular}

- Given the distance from the center to the fixed isothermal surfaces as $\mathrm{r}=0.0000$, $0.0002,0.0004,0.0006,0.0008,0.0010$ to calculate $\bar{t}(\mathrm{r}, \tau)=\bar{t}(\tau)$, the obtained results are shown in Table $3 \boldsymbol{a}$ and Table $\mathbf{3 b}$ as followings:

Table 2c. Variation of temperature according to $r$ at different frying times

\begin{tabular}{|c|c|c|c|}
\hline \multirow{2}{*}{$\mathrm{r}$} & \multicolumn{3}{|c|}{ Temperature after $\tau$ (s) of frying } \\
\cline { 2 - 4 } & $80 \mathrm{~s}$ & $90 \mathrm{~s}$ & $100 \mathrm{~s}$ \\
\hline 0.00000 & 149.68 & 149.86 & 149.94 \\
\hline 0.00005 & 149.68 & 149.86 & 149.94 \\
\hline 0.00010 & 149.69 & 149.86 & 149.94 \\
\hline 0.00015 & 149.69 & 149.86 & 149.94 \\
\hline 0.00020 & 149.70 & 149.87 & 149.94 \\
\hline 0.00025 & 149.71 & 149.87 & 149.94 \\
\hline 0.00030 & 149.72 & 149.88 & 149.94 \\
\hline 0.00035 & 149.74 & 149.88 & 149.95 \\
\hline 0.00040 & 149.75 & 149.89 & 149.95 \\
\hline 0.00045 & 149.77 & 149.90 & 149.95 \\
\hline 0.00050 & 149.79 & 149.90 & 149.96 \\
\hline 0.00055 & 149.81 & 149.91 & 149.96 \\
\hline 0.00060 & 149.83 & 149.92 & 149.97 \\
\hline 0.00065 & 149.85 & 149.93 & 149.97 \\
\hline
\end{tabular}

Table 3a. Variation of temperature over time at different radius values

\begin{tabular}{|c|c|c|c|}
\hline \multirow{2}{*}{$\tau(\mathrm{s})$} & \multicolumn{3}{|c|}{ Temperature of the noodle strand } \\
& \multicolumn{3}{|c|}{$t(\mathrm{r}, \tau)=\bar{t}(\tau)}$, \\
\cline { 2 - 4 } & $\mathrm{r}=0.0000$ & $\mathrm{r}=0.0002$ & $\mathrm{r}=0.0004$ \\
\hline $10 \mathrm{~s}$ & 61.04 & 65.69 & 79.18 \\
\hline $20 \mathrm{~s}$ & 109.49 & 111.80 & 118.32 \\
\hline $30 \mathrm{~s}$ & 131.92 & 132.95 & 135.87 \\
\hline $40 \mathrm{~s}$ & 141.93 & 142.39 & 143.69 \\
\hline $50 \mathrm{~s}$ & 146.40 & 146.61 & 147.19 \\
\hline $60 \mathrm{~s}$ & 148.40 & 148.49 & 148.75 \\
\hline $70 \mathrm{~s}$ & 149.28 & 149.33 & 149.44 \\
\hline $80 \mathrm{~s}$ & 149.68 & 149.70 & 149.75 \\
\hline $90 \mathrm{~s}$ & 149.86 & 149.87 & 149.89 \\
\hline $100 \mathrm{~s}$ & 149.94 & 149.94 & 149.95 \\
\hline
\end{tabular}


Table 3b. Variation of temperature over time at different radius values

\begin{tabular}{|c|c|c|c|}
\hline \multirow{2}{*}{$\tau(s)$} & \multicolumn{3}{|c|}{$\bar{t}(\mathrm{r}, \tau)=\bar{t}(\tau)}$, \\
\cline { 2 - 4 } & $\mathrm{r}=0.0006$ & $\mathrm{r}=0.0008$ & $\mathrm{r}=0.0010$ \\
\hline $10 \mathrm{~s}$ & 99.96 & 125 & 150 \\
\hline $20 \mathrm{~s}$ & 127.96 & 139.13 & 150 \\
\hline $30 \mathrm{~s}$ & 140.17 & 145.15 & 150 \\
\hline $40 \mathrm{~s}$ & 145.62 & 147.84 & 150 \\
\hline $50 \mathrm{~s}$ & 148.04 & 149.04 & 150 \\
\hline $60 \mathrm{~s}$ & 149.13 & 149.57 & 150 \\
\hline $70 \mathrm{~s}$ & 149.61 & 149.81 & 150 \\
\hline $80 \mathrm{~s}$ & 149.83 & 149.91 & 150 \\
\hline $90 \mathrm{~s}$ & 149.92 & 149.96 & 150 \\
\hline $100 \mathrm{~s}$ & 149.97 & 149.98 & 150 \\
\hline
\end{tabular}

- With the data in Table $2 \mathrm{a}$, Table $2 \mathrm{~b}$ and Table 2c, Matlab 8.0 software was used to simulate the frying process of instant noodles. The results obtained are shown in Figure 4.

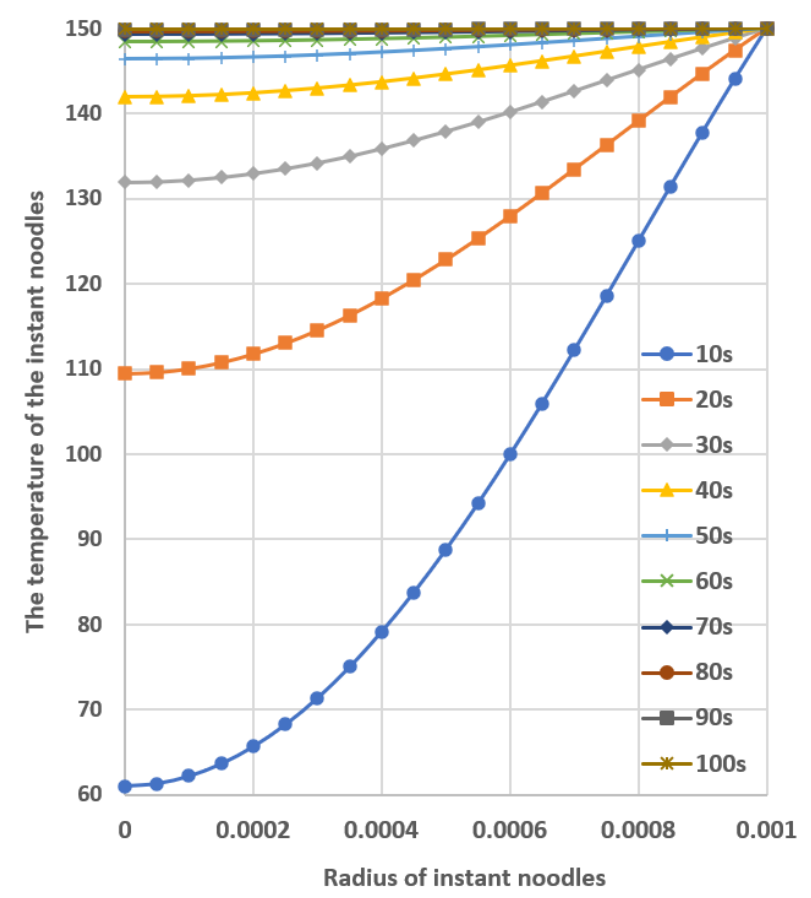

Figure 4. Relationship between frying temperature and radius of the noodle strands
- From the data in Table $3 a$ and Table 3b, Matlab 8.0 software was used to simulate the frying process of instant noodles. The results obtained are shown in Figure 5 as following:

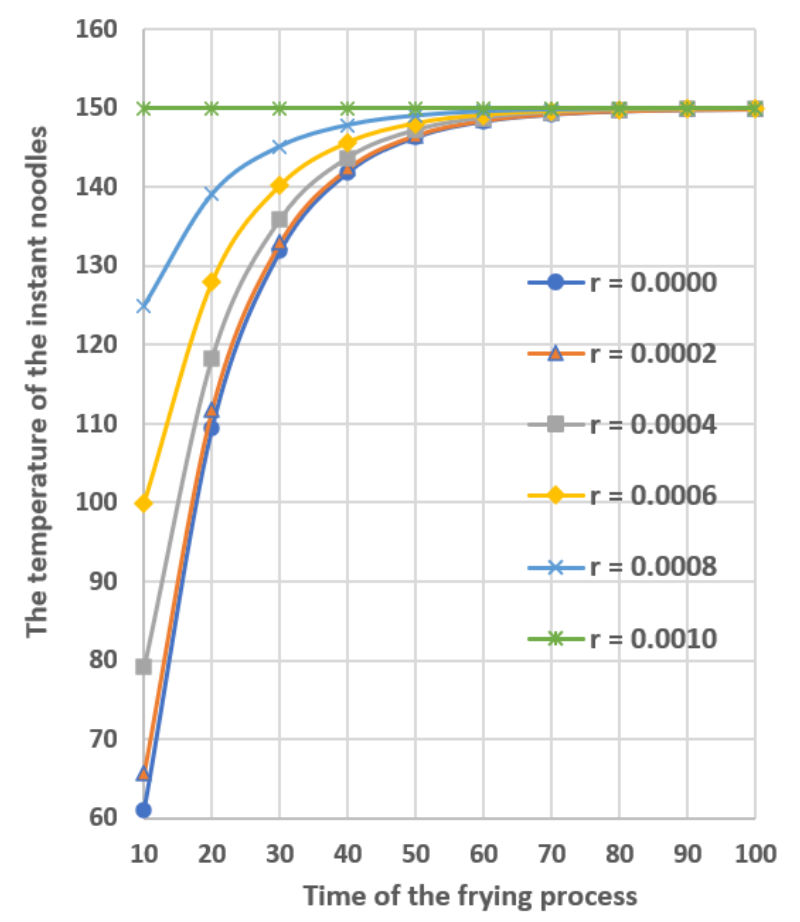

Figure 5. Relationship between frying temperature and frying time

- To validate the compatibility of the mathematical model, the error function $\operatorname{Er}(\%)$, the error between calculated data and experimental data, is normally used. Er (\%) of the model was calculated by the following equation:

$$
\mathrm{Er}=\frac{\left|\mathrm{T}_{\mathrm{M}}-\mathrm{T}_{\mathrm{E}}\right|}{\mathrm{T}_{\mathrm{E}}} .100 \%
$$

- If $\operatorname{Er} \leq \operatorname{Er}(p)$, where $\operatorname{Er}(p)$ is the permissible error, the mathematical model is considered compatible.

- $\quad$ If $\operatorname{Er}>\operatorname{Er}(p)$, the mathematical model is not compatible.

Technically, the maximum error of mathematical model is $\operatorname{Er}(\mathrm{p})=10 \%=0.1$.

On that basis, the surface temperature of the noodle strand with the radius $\mathrm{R}=1 \mathrm{~mm}=$ 
$0.001 \mathrm{~m}$ was determined by using the calculated data $\mathrm{T}_{\mathrm{M}}\left({ }^{\circ} \mathrm{C}\right)$ and by experimental data $\mathrm{T}_{\mathrm{E}}\left({ }^{\circ} \mathrm{C}\right)$. Equation (18) was used to calculate the temperature (Table 5).

Table 5. Temperature determined by mathematical model $\mathrm{T}_{\mathrm{M}}\left({ }^{\circ} \mathrm{C}\right)$ and by experiments $\mathrm{T}_{\mathrm{E}}\left({ }^{\circ} \mathrm{C}\right)$ when $\mathrm{r}=0.001 \mathrm{~m}$ (at the surface of noodle strand)

\begin{tabular}{|c|c|c|c|}
\hline$\tau(\mathrm{s})$ & $\begin{array}{c}\text { Temp, } \\
\mathrm{T}_{\mathrm{M}}\left({ }^{\circ} \mathrm{C}\right)\end{array}$ & $\begin{array}{c}\text { Temp, } \\
\mathrm{T}_{\mathrm{E}}\left({ }^{\circ} \mathrm{C}\right)\end{array}$ & $\begin{array}{c}\text { Error, } \\
\text { Er }(\%)\end{array}$ \\
\hline $00 \mathrm{~s}$ & 25 & 25 & 0.00 \\
\hline $20 \mathrm{~s}$ & 150 & 138 & 8.70 \\
\hline $30 \mathrm{~s}$ & 150 & 142 & 5.63 \\
\hline $40 \mathrm{~s}$ & 150 & 146 & 2.74 \\
\hline $50 \mathrm{~s}$ & 150 & 147 & 2.04 \\
\hline $60 \mathrm{~s}$ & 150 & 150 & 0.00 \\
\hline $70 \mathrm{~s}$ & 150 & 150 & 0.00 \\
\hline $80 \mathrm{~s}$ & 150 & 150 & 0.00 \\
\hline $90 \mathrm{~s}$ & 150 & 150 & 0.00 \\
\hline $100 \mathrm{~s}$ & 150 & 150 & 0.00 \\
\hline
\end{tabular}

Table 5 shows that, the error of the mathematical model was $\mathrm{Er}=8.7 \%<\mathrm{Er}(\mathrm{p})=$ $10 \%$. Thus, the mathematical models from (1) to (5) and their roots as equation (9) were compatible with the experimental data. Therefore, model (9) can be used to calculate and establish the frying conditions for the instant noodle.

Figure 4 and Figure 5 show that when the frying time was more than $60 \mathrm{~s}$, the temperature variation according to the radius of the noodle calculated by the mathematical model (9) reached the oil frying temperature, $150{ }^{\circ} \mathrm{C}$. These temperature curves were almost superimposable, which was completely consistent with the experimental results obtained in Table 5.

- Mathematical model evaluation: The advantage of model (9) is that it is simple and easy to use to calculate the frying process of instant noodles, to calculate and establish the frying conditions. The disadvantage of this model is that such physical parameters as heatgenerating coefficient, thermal conductivity coefficient, density, specific heat, heat source $\mathrm{q}_{\mathrm{v}}$..., are approximate values based on assumed compositions of noodles. Therefore, the result calculated by model (9) was different from experimental data at frying time of 20 seconds; the error value was $8.7 \%$, which was higher than 5\% (Table 5). However, when the frying time increased, the error between calculated data and experimental data was reduced. As the frying time was greater than $60 \mathrm{~s}$, the data calculated by model (9) were identical with the experimental data (Table 5). This shows that at the beginning of frying process when heat was provided for intensive heating and moisture removal, the boundary conditions of the model (9) would change as compared to the actual frying conditions, leading to a large error. As the frying time increased, the temperature of the noodle strands gradually reached the temperature of frying oil, the moisture content of the noodles hence reached the equilibrium moisture content, the boundary conditions of model (9) were more stable, hence the accuracy of model (9) increased and the calculated data were consistent with the experimental data.

\subsection{Determination the frying moisture of the instant noodles}

After being fried at different times, the moisture content of the products was then determined. The obtained results are presented in Table 6.

Table 6. Moisture contents of the noodles before and after frying at oil temperature of 150 ${ }^{\circ} \mathrm{C}$ (the radius of noodle strands was $\mathrm{r}=0.001 \mathrm{~m}$ )

\begin{tabular}{|c|c|c|}
\hline $\begin{array}{c}\text { Time of } \\
\text { frying } \\
\tau(\mathrm{s})\end{array}$ & $\begin{array}{c}\text { Moisture content } \\
\text { of noodles before } \\
\text { frying, } \\
\text { Wo }(\%)\end{array}$ & $\begin{array}{c}\text { Moisture content } \\
\text { of noodles after } \\
\text { frying, } \\
\text { We }(\%)\end{array}$ \\
\hline $00 \mathrm{~s}$ & 54.8 & 54.8 \\
\hline
\end{tabular}




\begin{tabular}{|c|c|c|}
\hline $10 \mathrm{~s}$ & 54.8 & 12.5 \\
\hline $20 \mathrm{~s}$ & 54.8 & 5.4 \\
\hline $30 \mathrm{~s}$ & 54.8 & 3.2 \\
\hline $40 \mathrm{~s}$ & 54.8 & 2.9 \\
\hline $50 \mathrm{~s}$ & 54.8 & 2.7 \\
\hline $60 \mathrm{~s}$ & 54.8 & 2.4 \\
\hline $70 \mathrm{~s}$ & 54.8 & 2.3 \\
\hline $80 \mathrm{~s}$ & 54.8 & 2.1 \\
\hline $90 \mathrm{~s}$ & 54.8 & 1.8 \\
\hline $100 \mathrm{~s}$ & 54.8 & 1.8 \\
\hline
\end{tabular}

It can be seen from Table 6 at two different frying times of $90 \mathrm{~s}$ and $100 \mathrm{~s}$, the two noodle samples had similar equilibrium moisture content $(1.8 \%)$. This moisture content was satisfactory for the exported product (Saguy S. and Dana, D., 2003), and the temperature of noodle strands reached the temperature of frying oil which was $150^{\circ} \mathrm{C}$. After frying, the noodles were well cooked and had a fine yellow color as shown in Figure 6.

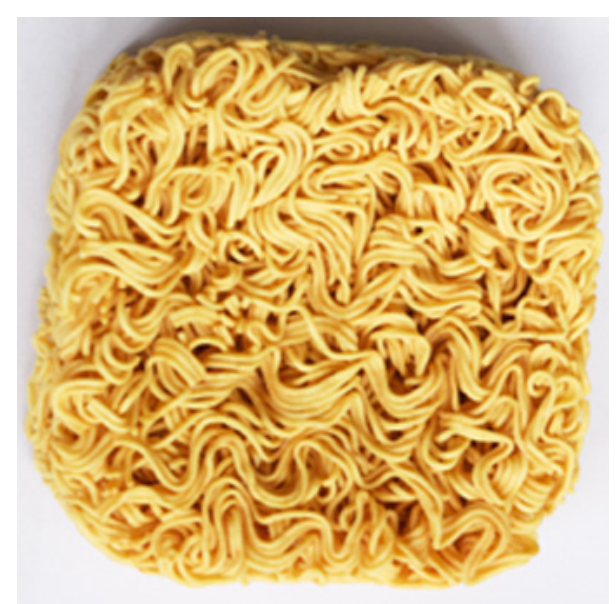

Figure 6. Instant noodles after frying for $90 \mathrm{~s}$, the moisture content reached $1.8 \%$.

\subsection{Determination of frying conditions for instant noodles}

From the above results, the frying conditions for raw noodle strands were established as following:

- Noodle had infinite cylindrical shape with the radius $r=0.001 \mathrm{~m}$;

- Frying time was 90s;

- Temperature of frying oil was $150^{\circ} \mathrm{C}$.

After frying at these conditions, the temperature of product reached $150{ }^{\circ} \mathrm{C}$ and moisture content after frying was satisfactorily $1.8 \%$. The resultant instant noodles were crispy and had a fine yellow color (Figure 6).

\section{Nomenclature}

$\mathrm{W}_{\mathrm{o}}=0.548=54.8 \%$ : Initial moisture of instant noodles

$\mathrm{c}_{\mathrm{p}}=2930.79\left(\mathrm{~J} \cdot \mathrm{kg}^{-1} \cdot \mathrm{K}^{-1}\right)$ : Specific heat of instant noodles

$\rho=1100\left(\mathrm{~kg} \cdot \mathrm{m}^{-3}\right)$ : Density of instant noodles

$\lambda=0.45 \quad\left(\mathrm{~W} \cdot \mathrm{m}^{-1} \cdot \mathrm{K}^{-1}\right): \quad$ Thermal conductivity coefficient of instant noodles

$\alpha=100\left(\mathrm{~W} \cdot \mathrm{m}^{-2} \cdot \mathrm{K}^{-1}\right)$ : heat emission coefficient of frying environment

$\mathrm{T}_{\mathrm{M}}\left({ }^{\circ} \mathrm{C}\right)$ : temperature of modelling

$\mathrm{T}_{\mathrm{E}}\left({ }^{\circ} \mathrm{C}\right)$ : experimental temperature.

$\tau$ (s) : frying time

$\mathrm{a}=1.395 \times 10^{-7}\left(\mathrm{~m}^{2} \cdot \mathrm{s}^{-1}\right)$, thermal diffusivity instant noodle strands

Bi: Biot number of instant noodles

Fo: Fourier number of instant noodles

\section{Conclusions}

- This study modeled the instant noodle frying process by using mathematical models from (1) to (5). This was an unstable heat transfer model which was suitable for instant noodle frying process in practical.

- Solving the mathematical models from (1) to (5) would obtain the solutions for the mathematical models represented by equations (6), (7), (8) and (9), in which model (9) was the general solution of the mathematical modelsfrom (1) to (5). Experiments also proved that model (9) were compatible with experimental data. Therefore, model (9) can be used to calculate the frying conditions for instant noodles as well as to design the deep frying equipment. 
- This study had established the conditions for frying instant noodles as follows: noodle strands had infinite cylindrical shape, with radius of $0.001 \mathrm{~m}$; frying time was 90 seconds; temperature of frying oil was $150^{\circ} \mathrm{C}$. After frying at these conditions, the temperature of product reached $150^{\circ} \mathrm{C}$ and moisture content after frying was satisfactorily $1.8 \%$. The product of instant noodles was crispy and had a beautiful yellow color (See Figure 6).

\section{References}

Akinsola A. O., et al., (2018). Frying of Food: A Critical Review. Journal of Culinary Science \& Technology., 16(2), 107-127

Benu, Adhikari, Xiaotian, Zhang, Min, Zhang., (2020). Recent developments in frying technologies applied to fresh foods. Trends in Food Science \& Technology, 98, 68-81

Bouchon, P., Aguilera, J. M., \& Pyle, D. L. (2003). Structure oil-absorption relationships during deep-fat frying. Journal of Food science., 68, 2711-2716

Shashi K.Pankaj, Kevin MKeene., (2017). A review and research trends in alternate frying technologies. Current Opinion in Food Science., 16, 74-79.

Costa, R. M., Oliveira, F. A. R. (1999). Modelling the kinetics of water loss during potato frying with a compartmental dynamic model. Journal of Food Engineering., 41(3-4), 177-185.

Gertz, C. (2014). Fundamentals of the frying process. European Journal of Lipid Science and Technology., 116, 669-674.

Dzung, N.T, et al., (2012a). Building The Method To Determine The Rate of Freezing Water of Penaeus Monodon, Carpathian Journal of Food Science and Technology., $4(2), 2012,28-35$.

Dzung, N.T, et al., (2012b). Building The Mathematical Model To Determine The Technological Mode For The Freezing Process Of Basa Fillet In ĐBSCL Of Vietnam By Experimental Method, Journal of Engineering Technology and Education, The 2012 International Conference on
Green Technology and Sustainable Development (GTSD2012),

Dzung, N.T., (2012). Application of MultiObjective Optimization by the Utopian Point Method to Determining the Technological Mode of Gac Oil Extraction. International Journal of Chemical Engineering and Applications., 3 (1), 1824.

Figura, L.O., Teixeira, A.A. (2007). Food Physics: Physical properties Measurement and Application, Germany, 554. http:// mechmath.org/books /82246

Heldman, D. R., Lund, D. B., Marcel Dekker, (1992). Handbook of Food Engineering, New York - Basel - Hong Kong 1992, $3550 \mathrm{p}$.

Holman, J., (1992). Heat Transfer, McGraw Hill, New York.

Saguy, S. and Dana, D. (2003). Integrated approach to deep fat frying: Engineering, nutrition, health and consumer aspects. Journal of Food engineering., 56,143-152

\section{Acknowledgments}

The author thanks Head of Lab B108 "Food Engineering and Technology", Department of Food Technology, Faculty of Chemical and Food Technology, HCMC University of Techmology and Education, Viet Nam, for their support and help to carry out the experiments. 